\title{
Risk, Profit, or Safety: Sociotechnical Systems under Stress
}

\author{
Burcak Erkan ${ }^{1}$, Gunes Ertan ${ }^{2}$, Jungwon $\mathrm{Yeo}^{3}$, and Louise K. Comfort ${ }^{3}$
}

This paper is prepared for submission to the Editors' Corner, 2014 Issue of Safety Science.

${ }^{1}$ Middle East Technical University, Ankara, TR; ${ }^{2}$ Koç University, Istanbul, TR; ${ }^{3}$ University of Pittsburgh, Pittsburgh, PA 15260, USA 


\title{
Risk, Profit, or Safety: Sociotechnical Systems under Stress
}

\begin{abstract}
Sociotechnical systems are designed to perform technical functions under organizational management for the benefit of society, but face major challenges in high risk operations such as mining. The mining industry in Turkey confronts a set of conflicting goals. Underground mining is a dangerous operation that creates continuing exposure to risk for miners who extract the coal. Yet, coal is an essential commodity for the growing Turkish economy, with mining operations now largely conducted by private companies seeking to maximize profit. Known strategies for managing mining operations to increase workers' safety exist and have been legally adopted in law and policy in Turkey, but require substantial investment of resources and time to put into practice. These same requirements in practice reduce profit to mining companies and slow production. The challenge is to balance these conflicting pressures in the mining industry to achieve low-cost energy for society, maintain safety for the miners, and ensure reasonable return on investment for mining companies. Achieving this balance in practice represents a classic collective action problem in which maximum benefit to the whole society can only be achieved by reasoned, informed action taken by multiple actors adapting to changing conditions under constraints of limited time and resources. These conflicting demands require a continual process of monitoring uncertain conditions, calibrating investment in safety in relation to cost of failure, and adapting to changing operating conditions in near-real time. We explore this set of conflicting pressures as a policy issue that confronts the mining industry globally, but inquire specifically into conditions that led to the deadly mine fire in Soma, Manisa, Turkey on May 13, 2014 as a study of a sociotechnical system under stress.
\end{abstract}

Key words: sociotechnical systems, industrial risk, coal resources, mine safety.

\section{The Mining Industry as a Sociotechnical System}

Conflicting goals among interdependent actors create cumulative stress in the underground mining industry. These goals include managing the technical constraints of underground operations, reducing physical risk to miners, and ensuring a profitable return to mining companies seeking to maintain their investment. These tensions are exacerbated by the mounting pressure for low-cost energy in rapidly advancing economies, and can be observed in many countries, for example, China, South Africa, India and Turkey (Sari et al. 2004; Geng and Saleh 2015; Leger 1991; and Maiti et al. 2009). Approached from a strictly linear perspective, each separate goal limits the achievement of other, related goals. Reducing the risk of accidents and fires in underground mining operations increases safety for the workers, but likely increases the cost of operations for the mining companies, reducing their margin of profit. Reducing the margin of profit for the companies likely limits their incentive to invest in mining operations, decreasing employment opportunities for the workers. Reducing employment opportunities for workers likely slows activity in other sectors of the economy, limiting the advancement of the wider society. Consequently, the risk in underground mining comes not only from the uncertainties embedded in the operation itself, but from the uncertainties exacerbated by the loss of the energy resource that coal provides to the wider society.

Given the sobering losses in lives and mounting costs in productivity that are reported repeatedly from underground mining operations that depend upon legal regulation, market incentives, and informed practice, we reframe the problem of managing risk in underground mining as an interdependent, sociotechnical system. In doing so, we ask four basic research questions: 1 . What major risks and benefits characterize underground mining? 2. Who are the major actors engaged in underground mining 
operations, and what are their points of potential conflict and collaboration? 3. What are the existing patterns of interaction among these actors? 4. What kinds of information and incentives would lead these interdependent actors to adapt their performance to create a sustainable, productive, safe mining industry?

Three interacting conditions contribute to recurring tensions in the mining industry: 1) risk inherent in underground mining, including risks associated with conventional (non-mechanized) panels (Sari et al. 2004); 2) margin of profit claimed by the mining companies; and 3) cost of safety measures, equipment, and training for the miners. Each of these conditions operates on a continuum that intersects with the other two conditions. The interacting relationships among these conditions can be framed as propositions to illustrate the interdependencies that confront public, private, and non-profit managers as they seek to balance the competing interests endemic to the underground mining industry. The propositions are;

As risk in the mining industry increases, the cost of safety measures also increases

As the cost of safety measures increases, the margin of profit decreases

As the margin of profit decreases, the investment in safety measures decreases

As the investment in safety measures decreases, risk in the mining industry increases

The conundrum posed by this circular set of propositions warrants further investigation and explication. First, conducting underground mining operations involves inherent danger, with the risk of spontaneous combustion, emission of dangerous gases, and collapse of roofs and rock falls in mine galleries (Duzgun 2014; Saleh and Cummings, 2011). Further, lack of mechanized panels increases the risk by escalating the impact of a possible accident, due to large numbers of workers in the underground mines at any given time. Reducing the risk of sudden threats in the internal operations of the mine requires a continuing investment in monitoring daily operating conditions, training miners to observe safety procedures, maintaining equipment in good operating condition, and building an informed knowledge base among all participants (Expert interview, Zonguldak, June, 2014). All of these actions are deemed essential, but they necessarily raise the cost of production and lengthen the time involved in the extraction of coal. Accurately calculating the cost of time, effort, and expertise essential to manage the risk of underground mine operations is fundamental to effective management of the mines.

Second, commercial companies engage in mining to make a profit, and consequently seek to keep costs low. This objective is further complicated by the tension between short-term profit and long-term sustainability of mining operations. If risky conditions are ignored and safety precautions are not taken, the mine may yield short-term profits that win fleeting political support, but belie the actual long-term costs of operations in an inherently dangerous industry. Consequently, unanticipated fires and sudden losses in manpower and production may erase short-term gains, making the mine unprofitable long-term.

Third, the cost of safety carries the implicit price of credibility of the mining industry as a reliable enterprise in a developing economy, as well as the credibility of decision makers, public and private, who assume responsibility for managing the system. If the larger benefit of mining is to produce energy for the welfare of the society, but, in fact, the price of that energy is paid with the lives of miners in an unprotected industry, the judgment of the political and private managers is called into question.

In summary, the dynamic tensions that drive the search to reduce risk, increase profit, and enhance safety lead the major actors committed to those goals in opposing directions, creating a thin margin for error in any direction. Managing the operations of underground mining involves high risk of economic loss to investors and threat to life and injury for miners, potential benefits in profits for private companies and steady jobs for miners, countered by high costs of failure in an industry characterized by high uncertainty and cascading interdependencies. To explore these tensions in more detail and consider an alternative model for managing this conundrum more effectively, we undertook a case study of the conditions, actions, and decisions that characterized the mine fire of May 13, 2014 in Soma, Manisa, Turkey. The 
remaining sections of this article follow in five parts. Section 2 will present a theoretical framework of complex, adaptive systems of systems to guide the inquiry. Section 3 will briefly describe the methods and data used in this analysis. Section 4 will summarize the context of underground coal mining in Turkey at the time of the Soma mine fire on May 13, 2014. Section 5 will describe briefly the operating conditions at the Eynez mine in Soma where the fire occurred, the actors engaged in mining operations and the interactions among them, as well as the points of actual breakdown and potential collaboration in the system. Section 6 will summarize the interdependencies among the actors, showing the cascade of decisions that resulted in the deadly fire, and possible strategies to reframe the interactions in a more constructive way through a Bayesian influence diagram. In Section 7, we draw conclusions from the analysis, and offer suggestions for considering the mining industry as a complex, adaptive system of systems, a more flexible, interactive framework for managing the inherent risk more effectively.

\section{Analytical Framework}

\subsection{The mining industry as a 'complex adaptive system of systems'}

The issues of mine safety and occupational health have attracted significant interest and attention by researchers in a range of disciplines: engineering, industrial safety, occupational health, geology, decision making, and psychology (Mallet et al. 1993; Braithwaite 1985; Jiping 2011; Bahn 2013). Much of the earlier research has treated the mining industry as a set of independent components that could be managed separately, without acknowledging the interactions among the components that make the system function or fail as a whole. For example, researchers have analyzed the design of engineering strategies for safer extraction of coal, but omitted the training needed for the miners to execute them. [Expert reference, Zonguldak, June 2014]. Others have designed mechanical devices to monitor toxic gases, but missed the time and expertise required to install the devices and analyze the data collected by them [Expert reference, Istanbul, June 2014]. Legal policies have specified regular procedures for inspecting the operating conditions in the mines, but failed to allocate the funding necessary to send experienced inspectors to the mines to conduct the inspections. [Mining Law, 1985; expert reference, Soma, May 2014] Recent research has considered the mining industry as a system (Saleh and Cummings, 2011), an insightful approach, but these authors still view the mining industry as a distinct system focused on its operational components.

In contrast, we propose that the mining industry operates as a sub-system embedded within the larger sociotechnical system of the wider society. This approach represents a 'complex, adaptive system of systems' (Glass et al. 2011), a set of concepts and metrics developed at Sandia National Laboratories to characterize and measure change in dynamic, interdependent systems as they adapt to new conditions and novel interactions among their components. A complex adaptive system emerges as a result of continued interaction of its constitutive actors. While the actors have some degree of independence and strategies, their behavior is very much constrained by the structure of the system that emanates from the totality of interactions. Similarly while the system constrains individual elements, the larger structure is also shaped by the aggregate behavior of its agents. Complex adaptive systems are dynamic systems that are highly adaptive to their external environments through changes in rules and actor level responses (Cowan, Pines, and Meltzer 1994; Holland 1995). In the 'complex, adaptive system of systems' approach, multiple systems are considered to be nested within each other and constitute a larger whole of interacting social and technical sub-systems. This approach uses an iterative process of defining a problem, designing a conceptual model for solution, and implementing the trial solution in actual practice, evaluating the results, and adapting the model as necessary to changing conditions (Glass et al. 2011). This iterative process means that all participants are actively involved in the design, monitoring, evaluation, and redesign of an evolving process. 
The mining industry, viewed as a sub-component of the larger societal system, is, in fact, an interdependent system of public laws, private investment, and voluntary compliance with industrial standards that produces energy, a valued resource for society. Identifying the major actors and their interactions (or lack of same) offers a systematic means of characterizing the performance of the mining industry as a complex, adaptive system embedded in the still larger system of the whole society. As in any dynamic system, underperformance in any one component triggers underperformance in related components and disrupts performance of the system, whether it is the mining industry as a whole, or as a contributor to the wider society. The reverse is also true, where distinctive performance in one component of the subsystem catalyzes effective performance in other components, leading to a readjustment or adaptation of the whole system.

\subsection{Legal structure of the mining industry in Turkey}

Using Turkey as an example, the structure of the mining industry is laid out in current laws, policies, and procedures governing underground coal mining that treat the industry as a separate system which can be controlled through regulation. Three pieces of legislation in particular govern the coal mining industry in Turkey. First, Article 168 of the Turkish Constitution (Chapter 2, Sec. 3, 1982) specifies that the government owns all natural resources, including coal. Consequently, the national government bears ultimate responsibility for managing the coal mining industry in Turkey. Second, under Law 3213, the Turkish Government may issue licenses to private companies to operate the mines (Mining Law, 1985). If licensed to do so, private companies then bear responsibility for the safe operation of mines. Finally, under Law 6331, workers have the right to stop work at any time, if they believe they are in danger (Occupational Health and Safety Law, 2012). Figure 1 shows interlocking relationships among the laws.

\section{<Insert Figure 1 about here>}

Figure 1. Diagram of laws, organizations, and functions governing the mining industry in Turkey.

While these three laws specify legal responsibilities for mining companies and rights for the workers that are consistent with standards in nations with long histories of policy and practice to protect mine workers, there is a substantial discrepancy between legal form and actual practice in Turkey.

As demonstrated in the figure, the Ministry of Energy and Natural Resources and one of its directorates, the General Directorate of Mining Affairs (MIGEM), are the two main organizations that regulate and oversee both production-related activities and safety in the mines. Legal authority over these two competing objectives, efficiency and safety, renders the Ministry of Energy and Natural Resources as the most powerful actor within mining policy in Turkey. In comparison to the Ministry of Energy and Natural Resources, the Ministry of Environment and Urbanization, the Ministry of Forestry and Water Affairs, and the Ministry of Labor and Social Security have rather peripheral roles in the policy system.

As shown, the current legal framework has no direct feedback from workers to management. Unions are organized to protect workers' rights, but operate largely under the aegis of the mining companies (Expert interview, Ankara, June, 2014). In practice, there is little capacity for enforcement of laws to ensure the safety of the workers or sustainable management of coal as a public resource (Expert interview, Ankara, June, 2014). Given the contrast between law and practice, the legal structure articulates clear goals for protection of workers and management of public resources, but lacks specific enforcement capacity, indicating underperformance in a crucial function that affects the whole industry.

\section{$\underline{2.3 \text { Commercial drive for profit }}$}


The underperformance in the legal structure governing the mining industry is offset by the strong commercial drive for profit demonstrated by the companies that operate the mines. As the Turkish economy has expanded in recent years, the demand for energy has increased, leading to increased pressure for production of coal. In 2013, Turkey became the $17^{\text {th }}$ largest economy in the world, and the $7^{\text {th }}$ in the region with $\$ 851.8$ billion in Gross Domestic Income (GDI). These figures are expected to rise to $10^{\text {th }}$ and $6^{\text {th }}$, respectively, in 2023. In 2013, Turkey's GDI is $\$ 0.7$ trillion, which is 4.5 times more than it was in 2002. The volume of the mining sector is $\$ 10$ billion in 2013, which is 6.8 times higher than in 2002. In 2002, the mining sector accounted for 0.92 per cent in total GDI of the country. In 2013, it is approximately 1.5 per cent of GDI, an increase of 52 per cent compared to 2002. During this time period, not only did the GDI increase by 4.5 times, but also the volume of the mining sector grew 6.8 times, with an annual production of $\$ 13$ billion (Turkish Statistical Institute, 2014). Inclusive of all side sectors of the mining industry, this number rounds to $\$ 22$ billion in economic worth.

Enabled by government licensing of the mines to private contractors and enticed by the expanding market for coal, private companies moved to take over mining operations that had largely been run inefficiently by government agencies. Committed first to efficiency and profit, but promising employment to workers and public benefit, the mining companies redefined the model of coal production. In practice, the mining industry represents a network of organizations engaged in commercial development of a public resource, coal, to produce energy to support economic development, unrestrained by rigorous legal requirements to protect the lives and safety of workers. The operation of the mining industry, with its strengths and weaknesses, can be understood as a dynamic driven in part by interdependencies among actors in the larger macro-system of economic, political, and social sub-systems that make up the Turkish society.

The mining industry is a labor-intensive segment of the economy that depends on human power. This segment makes an important contribution to the larger economy both as an energy resource for the production sector and as a source of employment. The mining industry has the largest share in the economy in terms of value added and the capacity to provide employment. It aids the development of the region where it is located, as 1 employee working in the mining industry contributes to 12 employment opportunities in related economic activity. There is high investor attention to the mining industry.

\section{<Insert Figure 2 about here>}

Figure 2. Electricity generation and proportional share by energy resources in Turkey, 1970 - 2014. Source: Data from TURKSTAT, 2014.

Figure 2 displays the distribution of energy sources used for electricity generation. Since the early 2000s, natural gas is the primary source of electricity generation, while the contribution of coal has declined steadily. However, coal remains the second largest contributor for electricity generation at $27 \%$.

\subsection{Cost of workers' safety.}

The primary group of actors in the complex system of underground mining is the miners. Without workers willing to do the dirty, dangerous work of underground mining, there would be no profit for the companies and no low-cost energy for the society. Yet, this group of actors has the least protection from risk and injury, and further, the least capacity to exercise their legally guaranteed right to refuse to work in unsafe mines without risking loss of their jobs in a tenuous economy. The mining industry is one of the leading occupational categories in terms of work-related deaths. In 2012, 13 per cent of work accidents originated in the mining industry. Within this industry, most accidents occurred in 'coal and lignite' mines. Between 1998 and 2001, 2554 people died due to work accidents and occupational diseases related to coal mining. Within the same time period, the number of permanent disabilities reported is 13,087 . 
In the Soma disaster, 301 miners and mining engineers lost their lives and 122 were injured. Among the fatalities, 78 per cent were under age 40 with an average age of 34 years. More than 80 per cent of the miners were primary or secondary school graduates, while 17 per cent were high school graduates. The remaining 3 per cent were divided between vocational school or university graduates with more than 1 per cent in each category. The relatively low rate of educational achievement among miners indicates a group of workers with little preparation to challenge existing authorities, even if their rights are formally granted.

While new technologies to enhance workers' safety are available, they are also expensive. For example, wireless headsets that can be attached to miners' helmets enable effective detection and communication during times of emergencies, but are rarely acquired by mine owners in Turkey due to high cost. Cameras installed in mine galleries can show the location and condition of workers at all times. Training courses for miners on safety techniques, considered essential by international standards of occupational safety and health, also require an investment in both time and money. Such investments reduce the margin of profit to the mining companies. For example, gas masks are required safety equipment for underground miners under Turkish law, but the quality and cost vary greatly. A well-designed gas mask that provides 3 hours of oxygen costs $\$ 450$. The cost of such gas masks for a typical shift of 700 miners would be $\$ 378,000$. Instead, inexpensive gas masks that cost approximately $\$ 50$ each and provided less than 45 minutes of oxygen were found in the Soma Eynez mine (Expert interview, Zonguldak, June, 2014). The difference in expenditure -- $\$ 378,000$ in comparison to $\$ 35,000$ - for required safety equipment would reduce the amount of profit for the company. The competing goals of profit and safety generate a sliding scale of reciprocal risk between the companies and the miners. Investment in safety is likely to reduce risk for the miners, but also reduce profit for the companies. Reduction in safety measures for the miners likely increases risk for the miners, but increases profit for the companies. Over the long term, the design, operation, and maintenance of mining as a sustainable industry depend upon the level of education, training, and capacity of the workforce (Expert interview, Zonguldak, June, 2014), which represents an investment by the wider society.

\subsection{Searching for balance in the complex, adaptive system of underground mining.} Managing the inherent risk in mining operations requires the identification of a wider network of actors and monitoring systems to identify potential threshold points of failure and adaptation to sustain operations. The uncertainties that characterize the physical, engineered, and organizational interactions in the mining industry are interdependent and leave little room for error in any direction. Reframing the mining industry as a sociotechnical system of interdependent actors and conditions allows rapid adjustment to changing conditions and enhanced sustainability of the industry's contribution to the wider society, but depends upon the creation of a shared knowledge base readily accessible to all participants.

Figure 3, below, illustrates the missing links in the current system of managing risk in the mining industry. While the provincial Disaster and Emergency Management Authority (AFAD) directorates are the main organizations responsible in case of a mining disaster, these directorates have limited experience

\section{<Insert Figure 3 about here>}

Figure 3. Interorganizational system for managing mine disasters in Turkey.

in responding to mining incidents and still lack formal integration with various actors that play a prominent role in mine rescue operations, most importantly with Tahlisiye teams specially trained for search and rescue in mines. The high number of deaths in the recent Soma mine fire highlights the critical role of safety in this industry. 


\section{Methods and Data.}

\subsection{Methods.}

We use a basic case study design to illustrate the policy conundrum intrinsic in underground mining operations (Yin 2013; George and Bennett 2005). Such an approach is useful in the initial stages of identifying and analyzing a complex policy problem, as it allows the characterization of a problem from actual practice for further analytical investigation and modeling (George and Bennett 2005). In this analysis, we identify the network of actors and conditions specified by the legal system for managing the operation of the underground mining industry in Turkey that was in effect on May 12, 2014. We contrast this formal network with the actual network of actors and conditions that were operating in the Eynez Mine in Soma on May 13, 2014 when a fire ignited in the mine, killing 301 miners, and the following four days that constituted the response operations.

\subsection{Data}

The data used in this analysis are collected from three different sources. First, we carried out a field study in the Soma District from May 29 - June 1, 2014, and conducted on-site observations at the mine site to understand the spatial and material conditions in which the incident occurred. Second, during this field visit, we conducted eight semi-structured interviews with personnel from local organizations in Soma, Manisa, Turkey. We corroborated observations from local personnel engaged in on-site operations with data from eight semi-structured interviews conducted with expert personnel responsible for managing response operations at national and provincial levels of jurisdiction in Ankara, Manisa, and Zonguldak. We conducted further interviews with four expert personnel from the mining industry in Ankara, Istanbul, and Pittsburgh. Several interviews were essentially focus groups and included multiple participants, increasing the overall representation from their particular perspectives, The interviewees represented a wide range of opinions; from extremely critical and scolding perceptions of the company and overall mining policy in Turkey to more sympathetic and pragmatic views towards the industry and company owners and personnel. All twenty scheduled interviews were conducted under standards of professional confidentiality without attribution to individual respondents to ensure candid assessment of actual conditions and operations at the mine. Further, we conducted a documentary review of relevant laws, policies, and procedures governing underground mining, health and safety requirements for mine workers in Turkey, with limited comparison to similar policies in the United States, China, and Ukraine. We also did a systematic review of news articles and professional reports regarding the event to identify the sequence of decisions that were made by government agencies, mining companies, and non-profit organizations to respond to the losses.

\subsection{Analytical techniques.}

We adopted the 'process tracing method (George and Bennett, 2005)' and analyzed the interview data from the aforementioned data sources in order to identify decision processes that triggered the actual incident. Based on the iterative analysis of interview data, we identified the major factors and decisions that were present or absent at the disaster situation. In addition, based on the frequency of those factors and the decisions documented in the interview data, we identified and assigned subjective priorprobabilities to those factors and actions as well as a subjective conditional probability of linkages among them. Then, we utilized the QGeNIe 2.0 modeling environment (Decision Systems Laboratory, 2013) to visualize the logic of the process tracing model in a Qualitative Bayesian Network and to transfer the posterior probability of the complex relationships among the identified factors and actions. The Qualitative Bayesian Network model thus describes the probabilistic relationships ${ }^{1}$ among factors and conditions of the decision processes that led to the mine fire. By presenting complex relationships among factors of risk, profit, and safety as well as identifying the most significant factors in the whole process, this Qualitative Bayesian Network model guides potential strategies of action for the mining industry,

\footnotetext{
${ }^{1}$ Subjectively perceived by each interviewee
} 
government agencies, and miners that illustrate the choices made (and not made) and their consequences in terms of achieving the overall goal of producing a sustainable source of energy for the country.

\section{The Context of Operations: Managing Risk in the Coal Mining Industry in Turkey}

\subsection{Ensuring safety standards in the minefields}

According to the Mining Law 3213, the Turkish Coal Enterprises (Turkiye Komur Isletmeleri, TKI) is the principal public organization that is charged with managing all coal mines in Turkey. ${ }^{2}$ While the state owns all mines in Turkey, TKI leases mines to private companies. Companies work on a system known as "rödövans" (redevance) in which the company pays for the contract by giving shares to the state from the coal they produce. In 2005, the Government gave all rights for coal mining to operating companies,

instead of charging for the coal they mine. ${ }^{3}$ After operating under this new system, the owner of the Soma Mining Company, Alp Gurkan, asserted that the company had decreased the cost of a ton of coal from \$130-140 to \$23. ${ }^{4}$ According to the 2010 amendments to Mining Law 3213, the company that undertakes production from the licensed owner must bear all the legal, financial and administrative responsibilities related to the implementation of the laws that regulate work place safety.

At the Soma mine, the licensed owner is Turkish Coal Enterprises (TKI), and the contracted operator is Soma Mining Company. Soma Mining Company secured the contract rights to the Soma mine in 2009 when Ciner Holding nullified its lease with TKI. According to statements by Ciner officials, the company left the mine due to frequent fires and safety concerns that were irreparable, since the original design of the mine had serious flaws. ${ }^{5}$

Table 1 demonstrates the amount of coal produced by state-run mines vs. private mines since the start of the "rödövans" system. Despite fluctuations, the amount of coal produced by privately operated mines in 2014 shows an increase since the initial year, 2000, reported over this period.

Table 1. Bituminous coal production in tons in Turkey 2000-2014.

Source: TTK Sector Report, 2015

\begin{tabular}{|l|l|l|}
\hline Year & State & Private \\
\hline 2000 & 2.259 .227 & 135.02 \\
\hline 2001 & 2.356 .865 & 137.1 \\
\hline 2002 & 2.244 .385 & 74.65 \\
\hline 2003 & 2.011 .178 & 47.94 \\
\hline 2004 & 1.880 .847 & 65.12 \\
\hline 2005 & 1.665 .846 & 511.36 \\
\hline 2006 & 1.522 .698 & 795.93 \\
\hline 2007 & 1.675 .283 & 817.09 \\
\hline 2008 & 1.586 .532 & 1.043 .909 \\
\hline 2009 & 1.879 .630 & 999.78 \\
\hline 2010 & 1.708 .844 & 883.07 \\
\hline
\end{tabular}

\footnotetext{
${ }^{2}$ http://www.taskomuru.gov.tr/index.php

${ }^{3} \mathrm{http}: / / \mathrm{www}$.hurriyetdailynews.com/soma-mine-operator-praised-lucrative-cost-reductions-in-previousinterview.aspx? pageID $=238 \& n I D=66448 \&$ NewsCatID $=345$

${ }^{4} \mathrm{http} / / /$ www.radikal.com.tr/turkiye/soma_holding_hakkinda_merak_edilenler-1192014

${ }^{5}$ http://www.zaman.com.tr/ekonomi_ciner-somada-tehlikeyi-gorerek-tkiyi-uyarmis_2231875.html
} 


\begin{tabular}{|l|l|l|}
\hline 2011 & 1.592 .515 & 1.026 .732 \\
\hline 2012 & 1.457 .098 & 835.16 \\
\hline 2013 & 1.366 .509 & 549.33 \\
\hline 2014 & 1.300 .154 & 488.19 \\
\hline
\end{tabular}

\subsection{The role of unions in enforcing mine standards}

The stated goal of the labor unions is to protect the rights and lives of workers, but in changing economies, the power of organized labor has weakened. While unionization rates have dropped in most advanced economies (Visser 2006, pp. 42-46.), unionization rates are low in the Turkish coal mining industry. According to the records of the Ministry of Labor and Social Security, by the end of 2013 there were about 200,000 coal mine workers and among them only 35,000, or $17.5 \%$, have union membership. ${ }^{6}$ Although subcontracting is not allowed in the mines in Turkey, testimonies from many workers reveal that the Soma Company still hires workers temporarily without any benefits or insurance ${ }^{7}$. The company utilizes certain loopholes in the law such as not hiring the workers as miners on paper, but by still sending them to work in the mines. In terms of maintaining international standards for workers' safety, Turkey has ratified only three of the twenty ILO conventions on workplace safety ${ }^{8}$. Among the 17 unsigned conventions, Convention no. 176, Safety and Health in Mines Convention, is the most crucial one that would ensure higher safety standards for miners. ${ }^{9}$

\subsection{Workplace Health and Safety}

In addition to the Mining Law 3213, the Law on Occupational Health and Safety 6331 provides the legal framework for the evaluation and implementation of workplace safety ${ }^{10}$. One of the critical articles of Law 6331 gives workers the right to cessation of work, if a worker perceives a life threatening condition in the workplace. The fact that workers never implement this right suggests limited safety education and a problematic risk culture among workers as well as pressures from superiors to ignore safety regulations ${ }^{11}$

\subsection{The Mine Inspection Process.}

MIGEM conducts a general audit every six months on mining fields to make sure that operations are in line with the mining law and regulatory statutes. Less extensive inspections are carried out every three months. MIGEM's inspection criteria are not clear and consist primarily of qualitative assessment. The lack of quantitative measurement prevents the agency from attaining a reliable risk analysis of mine operations and projections that may be used as decision criteria to determine if a mine field needs to be shut down (Duzgun, 2014).

Limited training and lack of experience of MIGEM inspectors are also highlighted in various evaluation reports even before the Soma incident (DDK, 2011). In addition to these factors, accounts from the field indicate that the exact time and date of the inspections are known to the mine managers, and sometimes arrangements are made to cover up safety violations. In addition to MIGEM, the Ministry of Labor and

\footnotetext{
${ }^{6} \mathrm{http}: / /$ www.bianet.org/bianet/insan-haklari/155785-turkiye-nin-komur-ocaklarinin-hikayesi

${ }^{7} \mathrm{http} / / /$ www.bianet.org/bianet/toplum/155799-bascavus-taseronu-anlatti

${ }^{8} \mathrm{http}: / /$ www.bianet.org/bianet/insan-haklari/155794-prof-dr-aktar-is-guvenligi-eksikligi-ab-ye-de-engel

${ }^{9} \mathrm{http} / / /$ www.hurriyetdailynews.com/turkey-refuses-to-sign-ilo-convention-regarding-safety-and-health-in-mines.aspx?pageID $=238 \& n I D=66502 \&$ NewsCatID $=347$

${ }^{10}$ Turkey had not ratified ILO Convention on Safety and Health in Mines(no 176) prior to the Soma disaster. The Turkish Constitution article 90 gives international agreements ratified by the Grand National Assembly the same statue as laws. Because of this firm legal position that ratified international agreements were granted that there had been calls on Turkey to ratify the convention after Soma, which Turkey in fact did later (/www.resmigazete.gov.tr/eskiler/2014/12/20141212.htm\&main=http: //www.resmigazete.gov.tr/eskiler/2014/12/20141212.htm).

${ }^{11}$ Our interview notes also indicate that the reason the largest number of deaths occurred in panel S, the panel furthest from the fire, was due to foremen's directives to workers to keep working despite alarm notifications.
} 
Social Security (MLSS) also conducts regular audits in coalmines. According to the MLSS, Soma mines were inspected just two months before the incident, and no violation of the Safety Law was detected or reported. MLSS audits are also criticized because the agency's auditors do not have specific coal mine expertise or use relevant inspection criteria. MLSS inspectors only check for general work place safety requirements, such as presence of a workplace physician, or adequate emergency equipment.

Finally, according to the Law 3213, each coal mine has to employ a technical supervisor ${ }^{12}$ (teknik nezaretci) who is responsible for reporting any safety related problems to the managers by filling out a "technical supervisor notebook" (teknik nezaretci defteri). Technical supervisors are mining engineers by education and visit a mine every two weeks, and work in multiple mines at a time (they are allowed to work in up to five mines). Unless a problem is identified in the technical supervisor's notebook, the technical supervisors are liable for any malfunctions or accidents in the mine, and mine managers and owners are exempt from legal action. After a problem is indicated in the notebook, mine management has to attend to the issue or is held liable if they fail to do so in case of an incident. However, the employer of the technical supervisor is also a member of the mine management team. Due to this conflict of interest, many technical supervisors do not want to risk their jobs by generating extra costs to their employers by revealing risks in the mines. This obvious flaw in the mine inspection system has been one of the most controversial and debated aspects of coal mining in Turkey for decades (TMMOB, 2010; DDK, 2011).

\subsection{Tensions among Risk, Profit, and Safety in Practice}

Despite formal policies and procedures in place to govern the mining industry, enforcement mechanisms appear lax in practice, with an absence of leadership or self organization among miners or communities to challenge infringements or create a shared understanding of safety as a bridge between risk and profit. Defining those tensions and making them explicit to build a broader understanding of the risks inherent in the industry, and the consequent need to invest in sustainable practice is a continuing policy problem.

\section{Extreme Event: The Soma Mine Fire, May 13, 2014}

\subsection{Operating conditions at the Soma, Eynez Mine before the fire}

The Soma Eynez Mine is located in the Eynez basin in Soma, a town of approximately 100,000 residents located in Manisa Province in western Turkey. The mine has been operated by Soma Mining Company since October 2009. The Eynez basin has rich lignite coal reserves, and the coal mined in the region is used in iron and steel industries as well as for operating the Soma Thermal Power Plant. Mining activity is carried out in underground mines using mixed methods, including the conventional longwall method with a limited number of mechanized panels. Due to the lack of mechanization in the mines, a large number of workers is underground at any time during the day.

\section{<Insert Figure 4 about here>}

Figure 4. Soma, Manisa Province, Western Turkey. Source: Google Maps

The Soma Eynez mine operates with three eight-hour shifts during any day of the year. The number of workers in any shift is around 700 to 800 . The mine is designed with different panels in which crews of miners are working simultaneously, using different types of mining techniques. The company employs, overall, about 3,000 workers and about 100 engineers. Similar to most lignite coal reserves in Turkey, the type of coal found in the Soma Eynez mine is highly susceptible to spontaneous combustion, as illustrated in various empirical investigations (Ozdeniz and Sensogut 2006; Kevin and Nicoloas 1986).

\footnotetext{
12 Technical supervisors of Soma mine are currently in jail waiting for trial along with production managers, and owners of the Soma Mining Company.
} 


\section{$<$ Insert Figure 5 about here>}

Fig. 5. Diagram of the Soma, Eynez Mine, showing location of mining panels A, C, S and mine exit.

The risk for spontaneous combustion is exacerbated by the extraction technique used in the Soma Eynez mine that leaves some of the coal behind. Witness testimonials assert that relying on subcontractors inside the mine substantially increases the amount of coal left behind because subcontractors are paid based on the distance of excavation, and not on the amount of production. Consequently, subcontractors are incentivized to excavate large areas without any concern for left over coal that may be exposed to oxygen and would increase the risk for spontaneous combustion.

Other operating conditions identified as contributing factors to the fire include: 1) an insufficient number of sensors that measure temperature as well as $\mathrm{CO}_{2}, \mathrm{CO}, \mathrm{CH}_{4}$ and methane gases; 2) lack of advanced tracking and communication technologies; 3) presence of inflammable equipment; and 4) outdated gas masks in scant numbers and 5) failure of the company to report the incident immediately to relevant authorities. (Expert Witness Report 2014; Ulutas, 2014; and TMMOB 2014).

\subsection{Timeline of Events ${ }^{13}$}

According to the Disaster and Emergency Management Authority (AFAD, 2014), the principal coordinating agency for response operations, the fire in the Eynez mine started around 2:59 p.m. on May $13^{\text {th }}, 2014$. Response operations concluded at noon on May $17^{\text {th }}, 2014$. The following section depicts the major events that took place during these days.

May $1^{\text {th }}$ : An explosion was reported to the media around 3.10 p.m. Later investigations revealed that over time, the $\mathrm{C}$ panel in the mine was filled with $\mathrm{CO}$ and $\mathrm{CH}_{4}$ gases, particularly in the area that was emptied after excavation. On the day of the incident, these gases reached to panel A, a major fresh air ventilation area. The fire quickly spread in panel A as it was exposed to high levels of oxygen and came in contact with the inflammable machinery of the conveyor belts. While most workers in Panel A were quickly evacuated, the largest number of deaths occurred in panel S, further away from Panel A, as there was no effective means of communication inside the mine to alert the miners to the fire.

Taner Yildiz, Minister of Energy and Natural Resources, arrived at Soma within hours, and told reporters there was no reliable information on the number of dead workers, or on the number of workers that were still in the mine. The Disaster and Emergency Management Authority (AFAD) declared 17 workers dead and 11 injured around 10 p.m., but did not provide any number for workers trapped in the mine. By midnight, 400 Search and Rescue (SAR) workers were seeking to extricate the trapped miners.

May 14 ${ }^{\text {th: }}$ Taner Yildiz declared 205 miners dead, and 80 rescued. He told reporters that the main cause of death was carbon monoxide poisoning. The Office of the Prime Minister declared 3 days of national mourning. Prime Minister Erdogan cancelled his schedule and arrived at Soma. The Manisa Fire Authority told reporters that the fire in the mine was still burning.

May 15 $^{\text {th: }}$ Taner Yildiz stated that the number of deaths rose to 282, and announced the start of an investigation into the fire. The Ministry of Family and Social Policies initiated a support program for family members of the deceased miners.

May 16 ${ }^{\text {th }}$ : The official number of casualties increased to 284. AFAD released the names of the deceased to respond to the criticism on lack of information about the identity of workers who were in the mine at

\footnotetext{
${ }^{13}$ Compiled based on interviews conducted with experts and actors that were involved in rescue operations after the fire.
} 
the time of the fire. Taner Yildiz stated that there were 18 miners still left in the mine. The prosecutor investigating the negligence involved in the incident issued a press release stating that they had started taking testimonies. The owner of the Soma Mining Company, Alp Gurkan, made his first public appearance and claimed there was no foul play in the incident. He also contradicted AFAD's statement that the cause of the incident was a fire in the power plant.

May $17^{\text {th. }}$ Taner Yildiz declared the total number of dead workers to be 301 . He also provided specific numbers of those injured, and those rescued without any injuries. The search and rescue operations were completed on this day. The ruling Justice and Development Party (AK Party) filed a request in the Parliament to conduct an investigation into the Soma incident, and to set up a nonpartisan committee on Soma incident.

\subsection{Network of actors engaged in response to the Eynez Mine Fire.}

The system of organizations that emerged in response to the Eynez Mine Fire quickly crossed both jurisdictional and sectoral boundaries as the crisis escalated from a local mine fire to become a national event. Reviewing newspaper articles, situation reports, and professional reports, a response system of 35 organizations was identified as being involved directly in actions related to the fire and the extrication of the dead miners. The organizations were identified by jurisdictional level and sector, and included 11 national agencies, 17 provincial agencies, and 7 private and nonprofit organizations. The national agencies included the major ministries, Energy and Natural Resources, Family and Social Policies, Internal Affairs, and Health, as well as Turkish Coal Enterprises, Turkish Military and AFAD, the national disaster management agency that operates under the Prime Minister's Office. The 17 provincial agencies included the governorships of near-by provinces that sent assistance and search and rescue teams. The private companies included the Soma Mining Company, the Imbat Mining Company, a neighboring mining company that responded within minutes to the disaster, two communications companies, and a soccer team. The Turkish Red Crescent organization was the only nonprofit agency included in the reports, although smaller, local groups contributed time and effort to care for the families of the miners. Since the list of participating organizations was derived from situation reports prepared by the Manisa AFAD Office to document its activities and interactions with other organizations engaged in response activities, the network revealed by these documents is a star network with the Manisa AFAD office as the central organization. The interactions among the organizations were not reported in detail, although the Minister of Energy and Natural Resources, Taner Yildiz, was most frequently cited as the spokesman for governmental actions, as shown in the timeline above.

\subsection{Contrast of actual performance with legal requirements}

The contrast between stated intent of the law and actual practice in the Soma disaster revealed a startling lack of preparedness in the Turkish disaster response system to manage a mining disaster of this scale. Following the devastating 1999 Marmara Earthquake, significant changes were made in the law and improvements in disaster preparedness (Corbacioglu and Kapucu, 2005). Most of these legal and institutional changes aimed at addressing earthquake-related risks. Therefore, the legal requirements for managing other types of hazards were not well defined when the Soma mining disaster occurred. Responding to a severe mine fire requires specially trained teams with specific equipment and experience. Neither state nor voluntary search and rescue personnel are qualified to participate in rescue operations, except the 17 Tahlisiye teams led by the personnel at Zonguldak's TTK Tahlisiye Training School.

The current regulatory framework locates provincial AFADs as the coordinating actor; however, AFAD as a coordinating agency was not prepared or equipped with experienced personnel to handle the specific requirements and risks of very dangerous rescue operations following the first three days after the incident. Overall, the specialized Tahlisiye teams need to be better integrated to the current formal disaster response system to avoid problems of coordination in similar types of disaster in the future. 


\section{Threshold points of failure and potential areas of change}

Identifying the points at which the larger system designed to manage the risks of underground mining failed in the Soma case creates an opportunity to review and redesign the system in a more effective way. Returning to the legal framework constructed to ensure safe management of underground mining operations, three sets of links are weak or missing, contributing to the breakdown of operations in the Soma mine. The first set includes links between the provincial AFAD offices and subsets of actors from the wider society that could provide skilled resources in local or regional disasters: 1) Turkish military units stationed in the region; 2) voluntary groups, such as psychologists and mental health workers; and 3) NGOs such as the Turkish Red Crescent. While these groups did offer assistance, the coordination was largely emergent and often initiated by the voluntary groups, without a clear framework for exchange of records and documentation of families served and families in greater need [Expert interview, Soma, May, 2014]. The second set of missing links was between the Occupational Health and Safety Program under the Ministry of Labor and Social Security and the Soma Mining Company. The absence of a clear line of responsibility between these two entities likely exacerbated the breakdown of norms of safe practice in mining that underscored their collective responsibility in ensuring that each miner exited the mine safely every night. The third missing link was between the TTK Tahlisiye teams and the Soma Mining Company, where the clash between safety and profit was likely the highest. While it is clear that these missing links contributed to the dysfunction in the Soma Mine, it is also noteworthy that these nonfunctioning links could serve as the first steps for corrective performance in the broader region.

\section{Interdependencies within the Operational System}

The timeline of reported actions documented the interdependencies among the actors involved in mining operations. Since the legal requirements for protection of the workers were not met in practice at the Soma mine, the drive for profit dominated operations in this complex system. Ironically, the focus on efficiency examined only short-term measures of efficiency, e.g. tons of coal produced per day, without including the long term costs of training, maintenance of equipment, and mechanization of the most risky tasks involved in excavating coal. The effort to cut short-term costs led to an inadequate supervision of daily work operations, equipment, and training, reducing efficiency over the long term as the work breakdowns, accidents, and injuries eroded the erstwhile profit that had been claimed. These conditions were further exacerbated by the narrow margin of error in any direction. In order to maintain the desired proportion of profit, the Soma Mining Company apparently deferred investments in training, mechanization, maintenance, and safety equipment, so that any unexpected malfunction triggered cascading errors in emergency decision making within the mine's operation. These errors included the initial decision by the engineers not to evacuate all workers in the mine immediately when they discovered the fire. Secondly, the engineers failed to provide explicit information on the status of the fire to relevant management personnel, or directions to accessible routes to safety to the miners working underground. Third, the workers failed to quit working and exit the mine, even as conditions in the mine worsened. Consequently, the legal requirements specified to reduce malfunctions in mine operations were overlooked, given the limited role of public supervision.

The consequences of this tightly coupled management strategy were very costly in all respects. In its impact on the workers, 301 miners lost their lives. In terms of efficiency in energy production, the Soma Eynez Mine was closed and out of production for months. In its impact on community well-being, the loss of jobs and dislocation for the miners' families had incalculable personal costs, as well as economic costs for the community. In its effort to compensate their losses, the national government paid out high welfare payments and made concessions to the families of the miners. In multiple dimensions, the event triggered economic, social, and psychological consequences that warrant serious reconsideration of the balance between risk, profit, and safety in the coal mining industry.

Based on information from the qualitative interviews with experienced managers in public agencies and expert observers from the mining industry, we traced the interdependencies among the sequential 
decisions by government officials, mining company CEO and managers, miners, and engineers that led to the sobering outcome of the Soma Mine Fire. Then, we modeled the complex processes in a Qualitative Bayesian Network shown below.

\section{<Insert Figure 6 about here>}

Figure 6. Qualitative Bayesian Network Diagram of Decision Processes leading to the Soma Mire Fire.

The nodes are the identified factors and conditions of Soma Mine incident. The arrows represent conditions of relationships among parent-nodes and their dependent child-nodes. The triangle arrows indicate parental nodes that cause the children nodes. The half circle arrows indicate that the presence of parental nodes that became the barrier to the presence of child-nodes. The square arrows signify that parental nodes are required for child nodes to be present. Lastly, the circle arrows imply that a parentnode inhibits child-nodes. In addition, the arrows carry information about conditional probability showing how likely child nodes will appear with the presence of the parental nodes. Initially, prior-probability is identified and assigned to each node based on data analysis. Then, based on identified sequence and conditions of relationships among parental nodes and child nodes, posterior probability of every node is updated. On Figure 6, the node colors indicate the degree of posterior-probability, with shades of red indicating lower probability of presence of the specific nodes and shades of green indicating higher probability of presence of the specific nodes.

The sequential set of decisions shows that the very low probability of strong government enforcement of regulations, coupled with the low probability of rigorous methods of inspection, leads to the high probability of disincentives for investing in employee safety and training activities. Importantly, the higher probability of discretion exercised by the mining company regarding employee safety and training leads to disincentives for investing in these activities. The diagram also shows the interconnected linkages between the number of fatalities and injuries due to carbon monoxide poisoning and the high impact and long-term costs following from this interacting set of conditions. The visual representation of these interconnected linkages enables policy makers and managers in government agencies, companies, and workers' groups to understand their interdependent relationships more clearly, and to see the long-term costs and consequences of decisions taken for short-term benefit. This type of analysis can benefit the management of the mining industry for all parties.

\section{Conclusions}

Returning to the four research questions posed at the beginning of this study (Sec. 1), the major risks and benefits that characterize underground mining are identified in our discussion of the trade-offs between risk, safety, and profit. The major actors engaged in underground mining operations are identified in the Qualitative Bayesian Network model (Figure 6) that also visualizes the potential points of conflict and cooperation among the actors. The existing patterns of interaction among these actors are documented in the timeline of events presented above (Sec. 5.2) and discussion of interdependencies (Sec. 6). The remaining question: "What kinds of information and incentives would lead these interdependent actors to adapt their performance to create a sustainable, productive, safe mining industry?" is the most challenging. Based on findings from this study, we offer five basic steps that would contribute to advancing the sustainability, productivity, and safety of the mining industry in Turkey.

\subsection{Redefine the underground mining industry as a complex system of interacting systems}

The sequence of decisions that led to the Soma Mine Fire illustrates the tensions among risk, profit, and safety inherent in the mining industry. If it were redefined as a complex system of systems, the management structure in this uncertain environment would likely be more effective. This redefinition would involve continual monitoring of risk in the mines, appropriate use of information technologies in 
mines to display the changing status of risk, recognition of the complexity of the mining industry, and adaptation to the limits of human, technical, and physical capacity in achieving societal goals.

\subsection{Implement current technologies to monitor working conditions in uncertain mining operations} Technologies exist to support decision makers in managing complex, risky operations. However, they provide no guarantee of safety, but rather support a collective effort to monitor uncertain operations. Integrating timely, accurate information essential to decision makers, in turn, increases the flexibility in time and resources to manage risk that was disproportionately borne by the workers and community in Soma.

\subsection{Calculate the costs of underground mining over the long term}

Balancing accurately the cost of safety measures against the actual losses in lives, injuries, and productivity is essential to the viability of the mining industry. This calculation builds on the potential links for networking among the components of an efficient mine operation presented in Figure 6. Detailed measurement of both costs and benefits will aid this process. For example, mapping the distance from the galleries to the exit, monitoring the condition of nonflammable conveyor belts used to move coal within the mines, training of the miners, effective ventilation, early detection devices for gas accumulation, support for union activities and government regulations can all be stated as examples of how a networked system functions as a tool to support the decision making process to reduce risk, increase safety, and enhance profit for underground mine operations.

\subsection{Acknowledge the continuing role of underground mining in Turkey's energy profile}

Underground mining operations constitute a sector that cannot be fully stopped in Turkey. There is a high demand for energy, where coal is a major source of the energy. Licensing of mine companies, regular and thorough inspection of mine operations, and well-trained employees in underground mines are recognized policies to reduce risk and increase safety. Coordination among the actors that are observed in Figure 6, resulting in increased efficiency in managing this high risk industry, will significantly improve safety standards, reduce risk and increase profit for mining companies in Turkey.

\subsection{Invest in safety measures for long-term sustainability of the mining industry in Turkey}

Achieving reliably safe operations in the underground mining industry requires investment in training, monitoring, advanced technologies for rapid information search and exchange among the major actors in this complex set of operations. The cost of these measures, viewed as investments, will likely return a more reliable performance over a longer period of time, reducing risk, increasing safety, and enhancing profit over the long term.

The May 13, 2014 Soma Mine Fire not be the last damaging event that Turkey will experience in this high risk industry. Rather, this devastating experience serves as a basis for martialing informed decision making regarding the implementation of essential safety measures and preparedness in underground mines in Turkey. This analysis further shares the Turkish experience with other underground coal mine operating countries, such as India and China that also have a high risk of mine accidents. Understanding this risk will aid in calibrating safety standards both in terms of governmental regulations and in terms of managerial operations in the field. Balancing risk against safety will likely increase the profitability of the mine companies over the long term. Underground coal mining will continue to be a significant part of energy generation for many countries in the future. Analyzing and understanding the existing risks is essential to reducing future hazardous conditions in the industry.

\section{Acknowledgments:}

We acknowledge, with gratitude, support from the Graduate School of Public and International Affairs and the European Union Center of Excellence, University of Pittsburgh; the Disaster Management, Implementation, and Research Center, Middle East Technical University, Ankara, Turkey, and the 
National Science Foundation, RAPID Grant, CMMI-1447234, for this research. We also acknowledge, with thanks and appreciation, the experienced officials, experts, mineworkers, and local personnel engaged in the mining industry for lending their time and knowledge to this study. For reasons of professional confidentiality, they are unnamed, but their insights and observations have significantly informed this study.

\section{References:}

AFAD, Report on Soma Mine Fire, 2014.

Bahn, S. (2013). Workplace hazard identification and management: The case of an underground mining operation. Safety science, 57, 129-137.

George, A. L., and Bennett, A. (2005).Case studies and theory development in the social sciences. Massachusetts, MA: MIT Press.

Braithwaite, J. (1985). To punish or persuade: Enforcement of coal mine safety. SUNY Press.

Cowan, G. A.; Pines, D.; Meltzer, D. 1994 Complexity, Metaphors, Models and Reality: Proceedings Volume XIX; Sante Fe Institute, Studies in the Sciences of Complexity, Addison-Wesley: Reading, Massachusetts.

Corbacioglu, S. and Kapucu, N. (2005). Critical Evaluation of Turkish Disaster Management System. Turkish Public Administration Annual, 32, pp. 53-72.

DDK (State Inspection Council of the Turkish Republic) report on Mining Industry, 2011.

Decision Systems Laboratory (1998-2013) *GeNie 2.0, Pittsburgh, PA: Decision Systems Laboratory, University of Pittsburgh, available at http://genie.sis.pitt.edu/

Duzgun, S. (2014). Assessment of May 13, 2014 Soma Disaster, Journal of Turkish Geological Engineers, Special Issue on Soma. (In Turkish)

Expert Witness Report prepared for the Prosecutor of the Soma Trial (2014). Downloaded from T24 website at http://t24.com.tr/files/bilirkisi_raporu_sf_8_125.pdf.

Geng, F., \& Saleh, J. H. (2015). Challenging the emerging narrative: critical examination of coalmining safety in China, and recommendations for tackling mining hazards. Safety Science, 75, 36-48

Glass, R. J., Ames, A. L., Brown, T. J., Maffitt, S. L., Beyeler, W. E., Finley, P. D., \& Zagonel, A. A. (2011, June). Complex Adaptive Systems of Systems (CASoS) engineering: mapping aspirations to problem solutions. In Proceedings of the 8th International Conference on Complex Systems, Quincy, MA (Vol. 26).

Holland, John H. Hidden order: How adaptation builds complexity. Basic Books, 1995.

Jiping, S. (2011). Research on emergency refuge system in underground mine. Coal Science and Technology, 39(1), 69-71.

Kevin, B., \& Nicoloas, S. (1988). Critical temperatures of some Turkish coals due to spontaneous combustion. Journal of Mines, Metals \& Fuels, 36(9), 434-436. 
Leger, J. P. (1991). Trends and causes of fatalities in South African mines. Safety science, 14(3), 169-185. Maiti, J., Khanzode, V. V., \& Ray, P. K. (2009). Severity analysis of Indian coal mine accidents-A retrospective study for 100 years. Safety science, 47(7), 1033-1042.

Mallett, L., Vaught, C., \& Brnich, M. J. (1993). Sociotechnical communication in an underground mine fire: A study of warning messages during an emergency evacuation. Safety Science, 16(5), 709-728.

Mining Law 3213, 1985. http://www.mevzuat.gov.tr/MevzuatMetin/1.5.3213.pdf.

Occupational Health and Safety Law, 2012.

http://www.csgb.gov.tr/csgbPortal/ShowProperty/WLP\%20Repository/csgb/dosyalar/kitap/kitap03_6331

Ozdeniz, A. H., \& Sensogut, C. (2006). Computer controlled measurement of spontaneous combustion in coal stockpiles of the Western Lignite Corporation, Turkey. Journal of University of Science and Technology Beijing, Mineral, Metallurgy, Material, 13(2), 97-101.

Saleh, J. H., \& Cummings, A. M. (2011). Safety in the mining industry and the unfinished legacy of mining accidents: safety levers and defense-in-depth for addressing mining hazards. Safety Science, 49(6), 764-777.

Sari, M., Duzgun, H. S. B., Karpuz, C., \& Selcuk, A. S. (2004). Accident analysis of two Turkish underground coal mines. Safety Science, 42(8), 675-69

State Supervisory Council (DDK). 2011. "Investigation of Work Place Accidents in the Mining Sector". (In Turkish). Downloaded from http://www.tccb.gov.tr/ddk/ddk49.pdf.

Turkish Statistical Institute (TURKSTAT), www.tuik.gov.tr, page visited several times in 2014.

Union of Chambers of Turkish Engineers And Architects (TMMOB). 2010. "Report on Mining Accidents". (In Turkish). Downloaded from http://www.maden.org.tr/resimler/ekler/9bd3e8809c72d94_ek.pdf . 2014. “TMMOB's Investigation on Soma Disaster". Downloaded from http://www.tmmob.org.tr/sites/default/files/somaraporu_0.pdf

Ulutaş M. (December, 2014), “Soma Mine Disaster and the Reality of Privatization”, Vol. III, Issue 12, pp.15-23, Centre for Policy and Research on Turkey, London, ResearchTurkey. (http://researchturkey.org/?p=7447)

Visser, Jelle. 2006. Union membership statistics in 24 countries Monthly Labor Review.(January): 38-49.

Yin, Robert K. 2013. Case Study Research: Design and Methods (Applied Social Research Methods), $5^{\text {th }}$ Ed., Thousand Oaks: Sage Publications. 


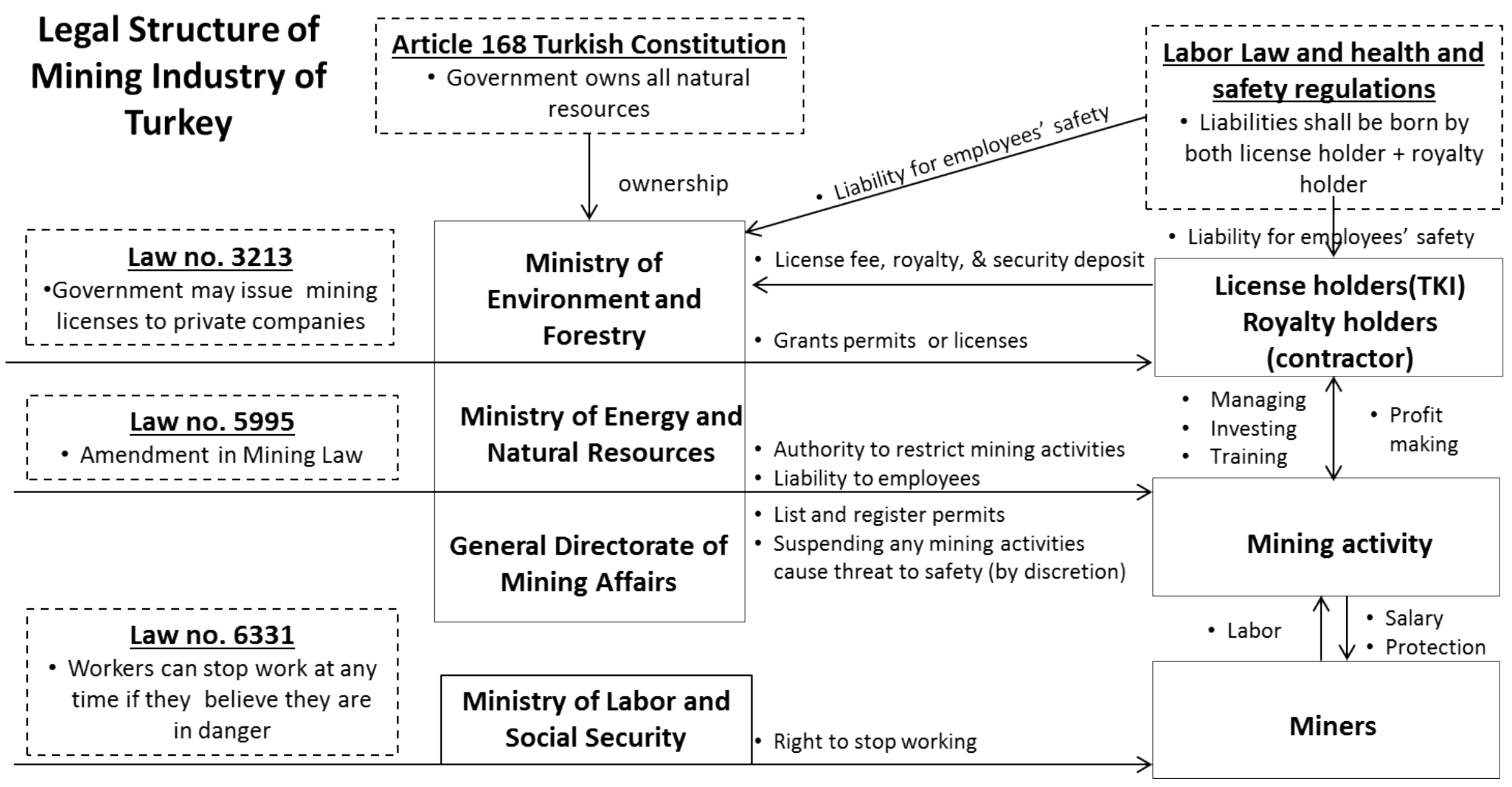




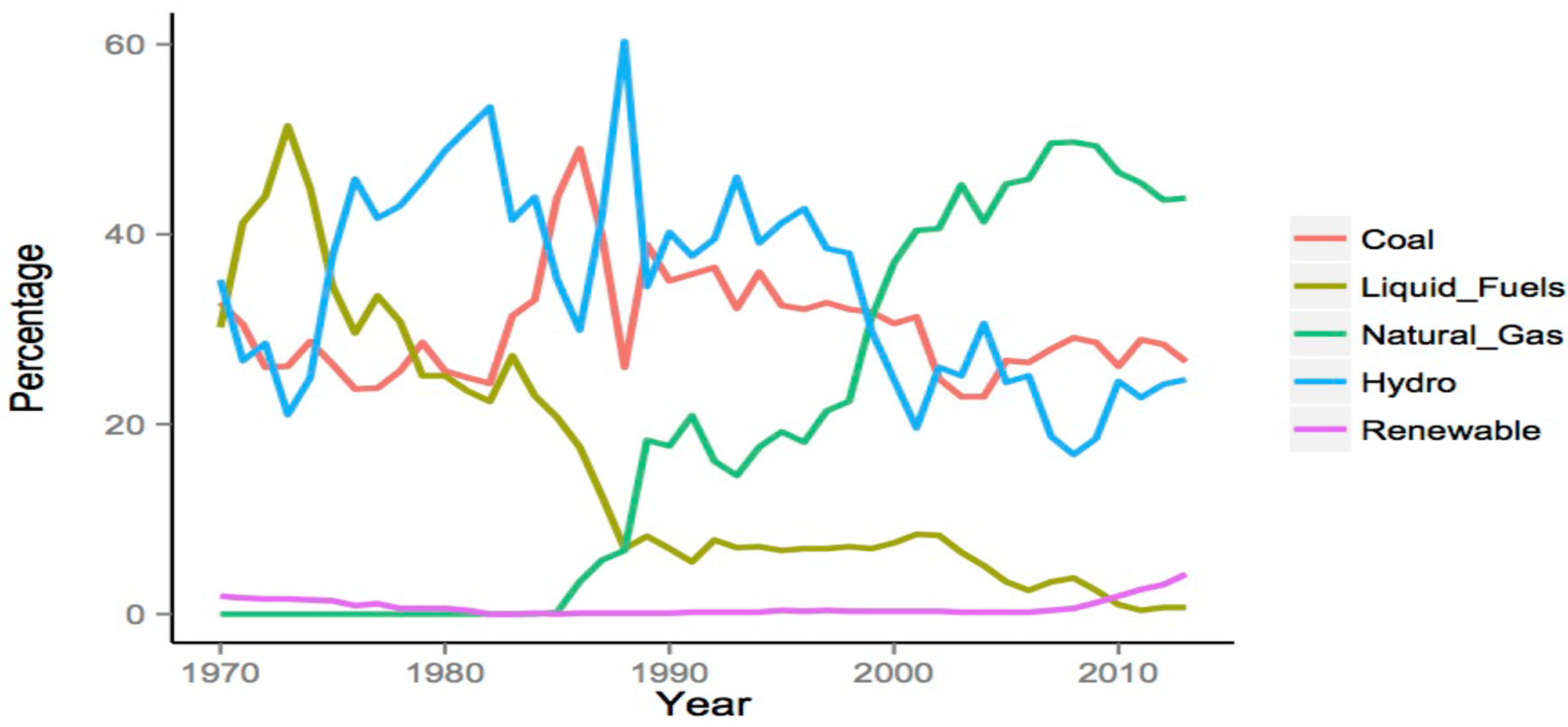




\section{MACRO/MESO-LEVEL DISASTER MANAGEMENT SYSTEM OF TURKEY}

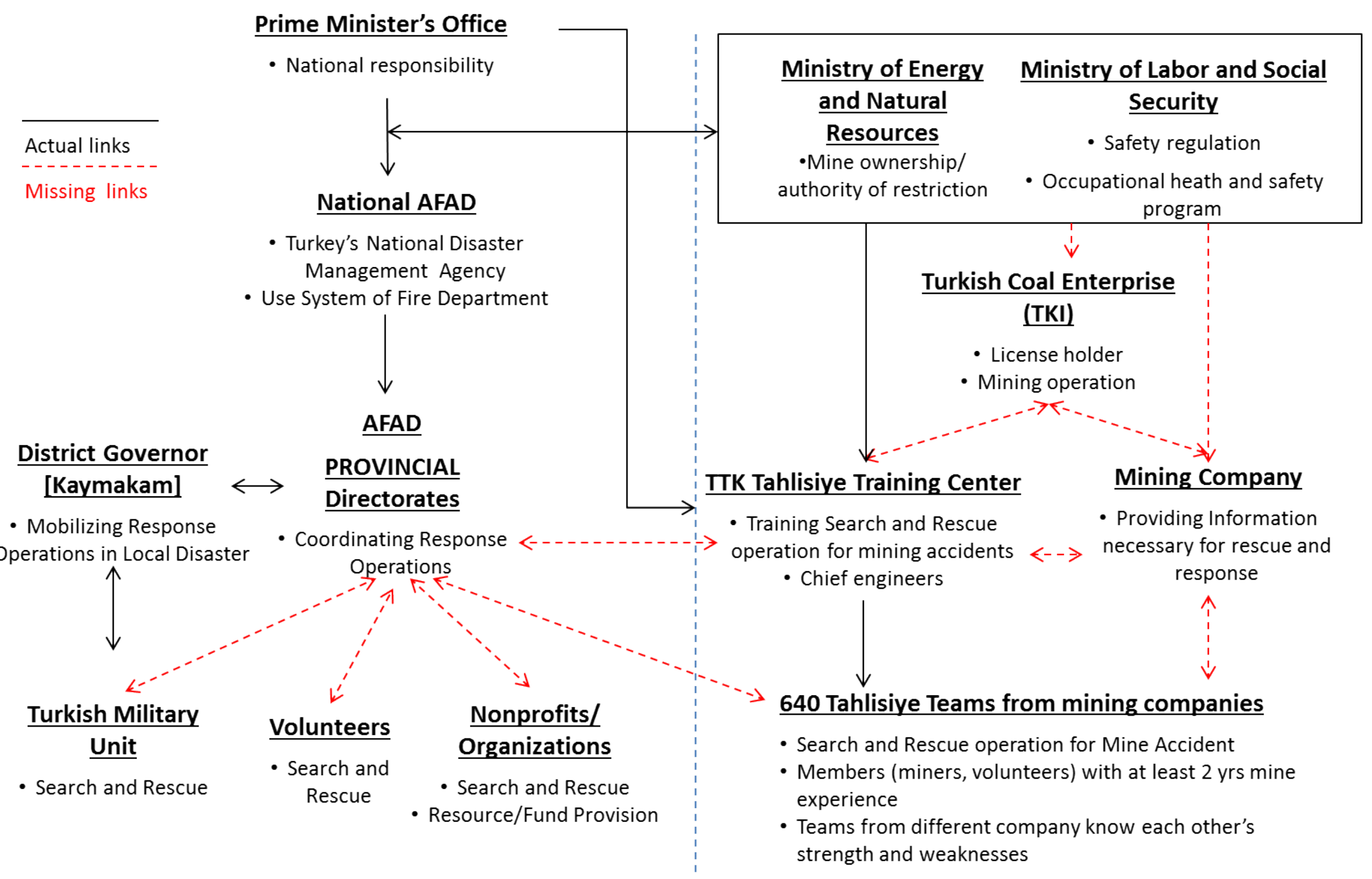

General System

Additional System In Mine Disaster 


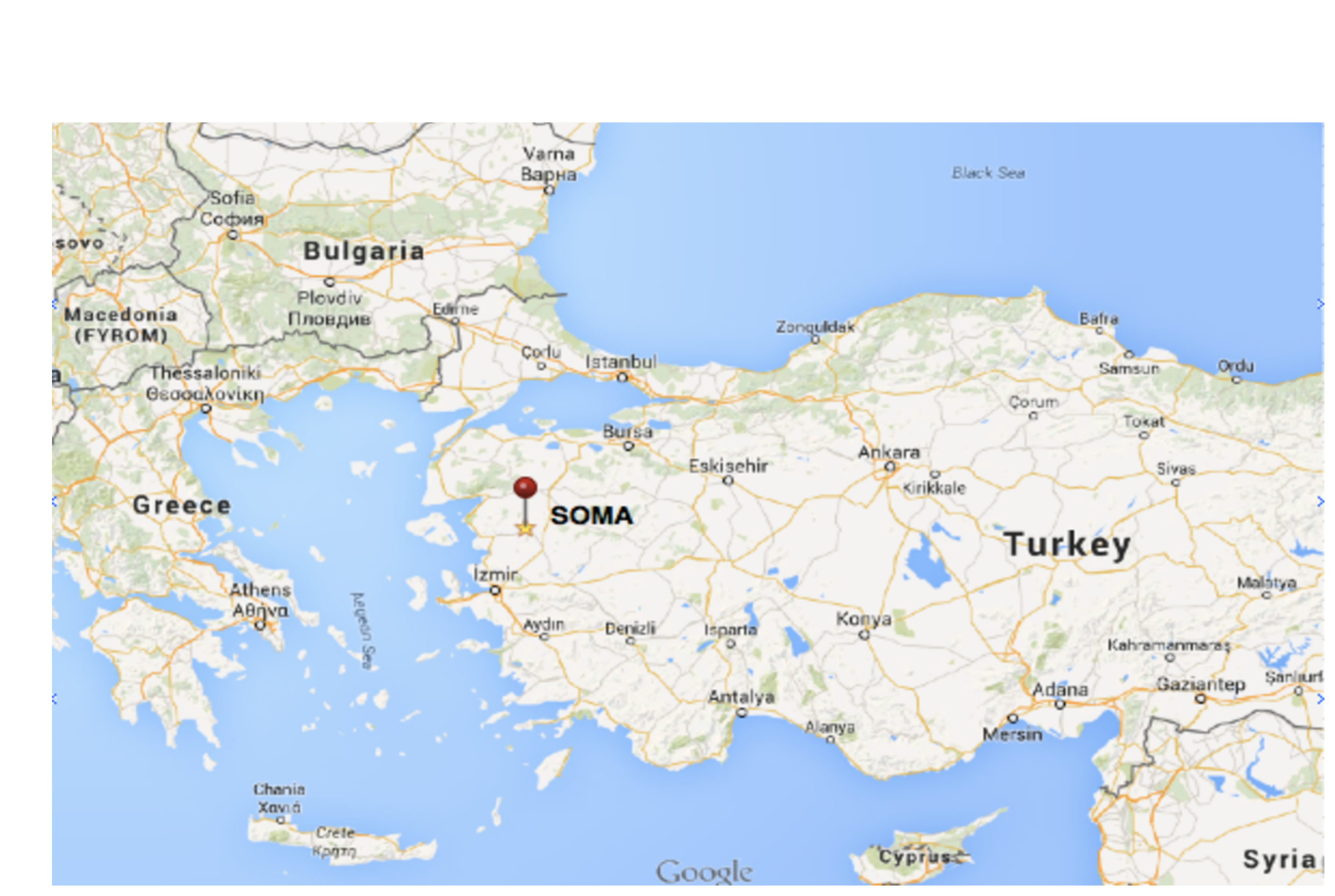


Figure 5

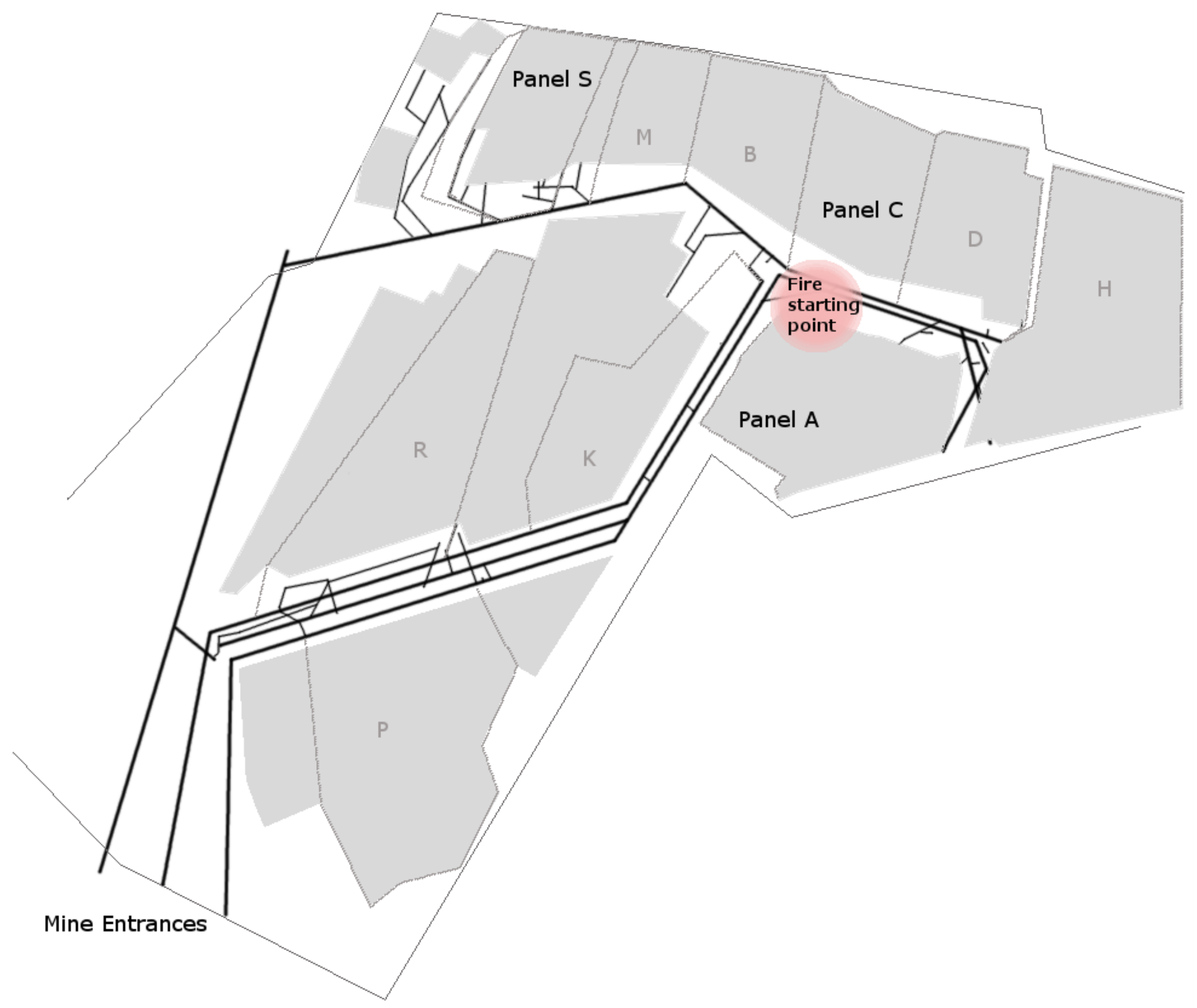


RED = LOWER PROBABILITY

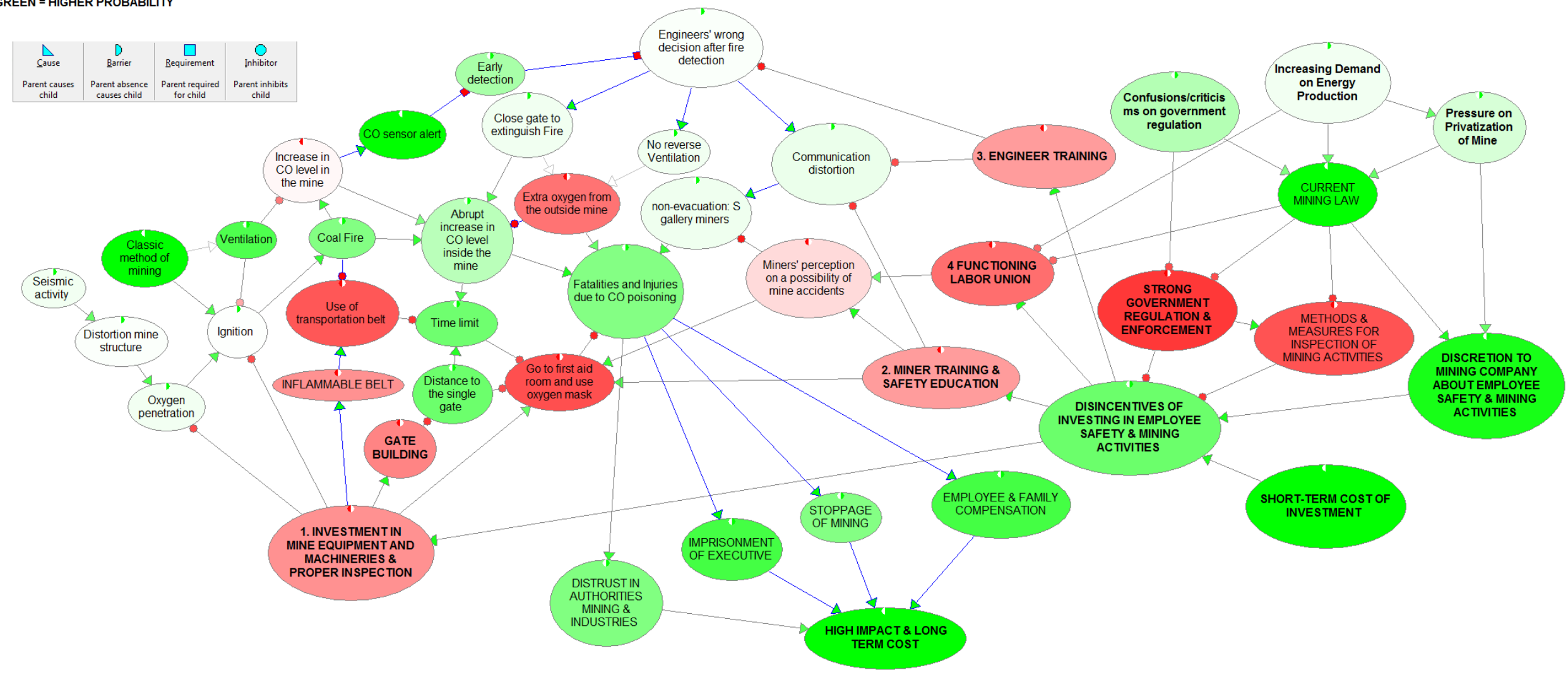

\section{Figure}

